\title{
Retraction Note to: Mass classification method in mammograms using correlated association rule mining
}

\author{
Aswini Kumar Mohanty ${ }^{1} \cdot$ Manas Senapati $^{2} \cdot$ Swapnasikta Beberta $^{3} \cdot$ Saroj Kumar Lenka $^{4}$
}

Published online: 26 October 2015

(C) The Natural Computing Applications Forum 2015

Retraction Note to: Neural Comput \& Applic

(2013) 23:273-281

DOI 10.1007/s00521-012-0857-x

The Editor-in-Chief has decided to retract this article. Upon investigation carried out according to the Committee on Publication Ethics guidelines, it has been found that the authors have duplicated substantial parts from the following article:

Classification Using Association Rules, Rajanish Dass W.P. No. 2008-01-05 January 2008

Indian Institute of Management, Ahmedabad, India

The online version of the original article can be found under doi:10.1007/s00521-012-0857-x.

Aswini Kumar Mohanty

asw_moh@yahoo.com

Manas Senapati

manas_senapati@sify.com

Swapnasikta Beberta

swapnasikta@gmail.com

Saroj Kumar Lenka

lenka.sarojkumar@gmail.com

SOA University, Bhubaneswar, Orissa, India

2 Krupajal Engineering College, Bhubaneswar, Orissa, India

3 BPUT, Rourkela, Orissa, India

4 Department of Computer Science, Mody University,

Lakshmangarh 332311, Rajasthan, India 